\title{
The Impact on the Pricing Process of Costly Active Management and Performance Chasing Clients
}

\author{
Ron Bird*, Lorenzo Casavecchia*, Paolo Pellizzari** and Paul Woolley***
}

\section{The Paul Woolley Centre for Capital Market Dysfunctionality, UTS Working Paper Series 3 \\ February 2009}

\begin{abstract}
One of the necessary features of markets to produce efficient pricing is competition between information-based investors who quickly impound new information into price. However, a significant proportion of funds invested in today's equity markets are in the hands of managers who pursue a style that utilises little or none of the available information. We simulate such a market where the funds are being managed using the following three investment styles: fundamental, momentum and index. We confirm that the major pricing anomalies that have been highlighted previously in the literature are a natural consequence of competition between managers utilising these three investment styles. More importantly, we show that this situation is unlikely to change as long as markets continue to be dominated by costly active managers with clients who pursue outperformance.
\end{abstract}

* Paul Woolley Centre for Capital Market Dysfunctionality, University of Technology Sydney.

** Dept. of Applied Mathematics, Ca' Foscari University of Venice.

*** Paul Woolley Centre for the Study of Capital Market Dysfunctionality, London School of Economics.

\footnotetext{
${ }^{*}$ The authors would like to acknowledge the generous donation by Paul Woolley when establishing the Paul Woolley Centre at the University of Technology Sydney (UTS). The work was largely completed while Paolo Pellizzari was visiting the Centre at UTS. His work is also supported by PRIN 2007 grant 2007TKLTSR, "Computational markets design and agent-based models of trading behavior". Corresponding author: Ron Bird, University of Technology, Sydney, PO Box 123 Broadway NSW 2007, phone +612 95147716, ron.bird@uts.edu.au
} 


\section{Introduction}

The informational efficiency of equity markets is largely driven by the availability of information and the impounding of this information into prices by information-based investors. In reality, the prime investors in these markets are fund managers who manage funds on behalf of their clients utilising a range of investment styles, many of which are not information-based. Indeed, over the last 40 years we have seen a drift away from information-based fundamental investing to investment styles such as indexing and momentum investing which draw minimally upon the rich set of information available to the investor.

The main focus of this paper is on examining the interplay between managers pursuing a range of investment styles and their clients with our objective being to provide insights as to the implications of their behaviour for the pricing process and so market efficiency. Other authors have already established that index managers and particularly momentum managers have a harmful impact on the efficiency of pricing within equity markets (e.g. Bird et al., 2005). We will confirm this finding in this paper within a realistic market setting where clients switch between managers based on their after-fees performance. Indeed perhaps the most important contribution of this paper stems from the insights that we provide as to the impact that clients have on market pricing as a consequence of their typical behaviour of chasing investment performance (Sapp and Tiwari, 2004, Bu and Lacey, 2008). A second important insight that can be gleaned from this paper is the implications for market efficiency of the costs incurred (and so the fees charged) by managers pursuing different styles. Indeed, we corroborate the Grossman and Stiglitz (1980) proposition that the costs associated with the information search that is so important in establishing efficient pricing will cause clients to "free ride" by investing in index funds and so ensuring that markets never become truly efficient. As an extension of this we also find that the lower costs associated with implementing a momentum strategy contribute to the survival of these types of investors in a world where afterfees performance is of paramount importance to clients. Of course, it is just these momentum investors that cause the greatest disruption in market pricing. Finally, and related to these other issues, we provide insights into the performance of both the different styles of investing and also the different strategies employed by clients for switching their funds between managers.

The remainder of the paper will be structured as follows. In Section 2 , we provide a more detailed background on the evidence relating to the different investment styles, the behaviour of clients and their relevance for efficient pricing. We spell out our model in Section 3 while reporting on the findings from our simulations in Section 4. We will conclude in Section 5 with a summary of our findings. 


\section{Background}

Fama (1970) highlighted the importance of the role played by rational, information-based investors in the formation of efficient pricing in capital markets. It was Grossman $(1976 ; 1977)$ and Grossman and Stiglitz (1980) who brought to our attentions the underlying paradox of the existence of efficient markets where all the information can be backed out of the prices. They stated that if in a competitive equilibrium arbitrage profits are eliminated by fully informative prices, it is impossible for the economy to be in equilibrium in the first instance, consequently opening a breach in the efficient market hypothesis. Figlewski (1978) extended the Grossman and Stiglitz's model to the case where the accumulated wealth of agents constitutes a determinant of each agent's demand. In such a setting the market only becomes informationally efficient if the distribution of wealth converges to a Pareto-optimal allocation.

More recently, Sargent (1993), Arthur (1995) and Hommes (2001) questioned the realism of the assumption of strong rationality, and tested whether efficient pricing would evolve in a market where traders are only boundedly rational. Hong and Stein (1999) developed a framework where the interaction between informed traders (newswatchers), and uninformed (momentum) traders, both with constant absolute risk aversion (CARA) and bounded rationality, are able to explain the commonly found initial underreaction to an information release followed by a subsequent overreaction to a series of information releases. This stream of research stimulated the development in recent years of a literature in heterogeneous agent-based models (HAM), comprising financial markets populated with agents who are neither fully-rational nor utilise the full information set (see also Brock and Hommes, 1997; 1998, Lux, 1995; 1998, Brock and LeBaron, 1996, Farmer and Joshi, 2002, and Iori, 2002). Many of these models have relied on computational methods to evaluate the impact on the price formation process of different beliefs about the future evolution of prices (see $\mathrm{He}$ and Li, 2008) and incorporated learning processes based on the relationship between market prices and available information. The evolutionary learning dynamics have been implemented using various tools, such as genetic algorithms based on fitness functions (Lettau, 1997), neural networks structures where traders learn on lagged prices (see Beltratti and Margarita, 1992), and adaptive belief models based on discrete choice probability (Brock and Hommes, 1997).

One common element of these various models is that they attribute the learning process directly to the clients, who evaluate the performance of their investment strategies, and consequently adapt by switching from a poor performing strategy to another which on recent evidence offers more promise (see for instance, Lux, 1995; 1998, and Lux and Marchesi, 1999; 2000). In contrast, the paper by Berk and Green (2004) propose a model where where clients react to past managerial performance. Since the agent's role in capital 
markets is performed by investment managers who commit themselves to a particular investment style through contracts stipulated with clients, we propose a more realistic setting where market evolution is driven by the choices of managers made by the clients. Therefore we develop a dynamic model where the fund flows to investment managers are determined by the decisions made by the ultimate investor (clients) as to who will manage their funds.

There are two critical assumptions in our model relating to the clients' investment behaviour. First, clients learn about unobservable manager ability only from their realised past fund performance. Starting with Gruber (1996), a branch of the mutual fund literature concentrated its attention on the existence of a smart money effect in markets (see Zheng, 1999 and Sapp and Tiwari, 2004), which refers to the investors' proclivity to identify superior managers based on their recent performance with the important consequence that funds flow from under-performing managers to out-performing managers. We decided to impound in our model this performance chasing behaviour of investors by incorporating a switching strategy for clients whereby they periodically reallocate their funds from the worst performing managers to the best performing manager. To our knowledge, our analysis constitutes the first attempt in the literature to translate the allocation of money flows by the clients into an indirect learning process for the market. Moreover, although unrealistic, we will assume for simplicity and model tractability that clients would shift 100 per cent of their funds that they have invested with the worst to the best manager, regardless of their investment style and any risk connotations.

Second, we recognise that clients pay a fee to managers based on the dollar value of the funds managed on their behalf. At a general level, the clients (principals) turn to the managers (agents) because they do not have the expertise and/or the time to manage the funds on their own behalf. The managers incur costs in performing the task assigned to them and so charge a management fee to both cover the costs associated with implementing their strategy and provide a return to compensate for their business risk. As these costs and each manager's business risk will vary with their style of investment, we would expect to see similar corresponding differences in the fees that they charge. Once we recognise the imposition of management fees, we also have to recognise that the clients will measure manager performance on an after-fees basis resulting in their switching behaviour being based on after-fee performance. One possible consequence of this is that only a small number, if any, are likely to be able to outperform the benchmark.

Finally, our boundedly-rational agents extend beyond the fundamental (rational information-based) manager to also include momentum (trend followers) and index (passive) managers. As mentioned previously, it is competition between fundamental investors that drive efficient pricing in markets. Below, we establish that this is the case but we also establish that the re- 
turns generated in a market entirely populated by fundamental investors do not have statistical properties equivalent to those observed in real markets. We go on to show that it is the interplay between managers following differing investment styles combined with clients who chase after-fee investment returns that give rise to a price formation process, and the realisation of returns, that is typical of those observed in markets.

\section{The model}

This section describes the model of a simple financial market with one risky asset (stock) and a riskless asset (cash) that pays a quarterly interest of $r_{f}$. The typical time-step in the model is one week with a quarter and a year being defined as periods of 13 and 52 weeks, respectively. Let $p_{t}$ denote the cum-dividend price of the stock at week $t$. Being the unique risky asset in the market, we also refer to $p_{t}$ as "the benchmark" of the market. The following subsections will outline the details but it is useful at this stage to outline the main features of the model:

1. Managers can trade a riskless asset and a risky stock whose fundamental price is related to a stochastic earnings growth rate that is announced every quarter;

2. Managers manage funds on behalf of clients using a range of investment styles. It is the excess demand of these managers that drives the price of the risky asset;

3. Managers charge a fee for managing funds on behalf of clients who periodically evaluate their after-fees performance and have a strategy for switching their funds between managers based on this performance.

\subsection{The economy}

The fundamentals in this economy are driven by the quarterly announcement of the stochastic earning growth rate $g_{t}$ :

$$
g_{t}= \begin{cases}g_{0}-\theta\left(g_{0}-g_{t-1}\right)+\sigma \epsilon_{t} & \text { if } t=13 k, k=1,2, \ldots \\ g_{t-1} & \text { for all other } t^{\prime} \text { 's }\end{cases}
$$

where $g_{0}$ is the long term mean of the process, $\theta \geq 0$ is related to the speed of mean reversion to $g_{0}, \sigma$ is the standard deviation of the noise term and $\epsilon_{t} \sim N(0,1)$. Hence, $\left\{g_{t}, t=1, \ldots\right\}$ is a piece-wise constant process that jumps every quarter (13 weeks) when a new value for earnings growth is made public. The mean reverting process that is used to model the growth rate can be specified so as to incorporate some special and important cases. Setting $\theta=1$, for example, produces quarterly independent normal growth 
rates with mean $g_{0}$. However, when $0<\theta<1$ there is some degree of serial correlation among subsequent earning announcements that is consistent with the empirical literature (Soffer and Walther, 1999).

The fundamental price $p_{t}^{*}$ of the stock at time $t$ is a piece-wise constant with jumps corresponding to the announcements Its value can be computed using the Gordon model to give

$$
p_{t}^{*}=\frac{\lambda e_{t}\left(1+g_{0}\right)}{r-g_{0}}
$$

where $\lambda>0$ is the fixed payout rate, $r$ is the cost of equity and the earning per share $e_{t}$ is given by:

$$
e_{t}= \begin{cases}\left(1+g_{t}\right) e_{t-1} & \text { if } t=13 k, k=1,2, \ldots \\ e_{t-1} & \text { for all other } t \text { 's }\end{cases}
$$

\subsection{The managers}

We consider several representative fund managers in the market who differentiate themselves on the basis of their investment style which is reflected by their distinct excess demand functions. If $X$ is the set of managers, we define the excess demand of manager $x \in X$ at time $t$ as

$$
z_{x t}=w_{x t} f_{x t}\left(p_{t} \mid \Theta_{t}\right),
$$

where $w_{x t}$ is the market share of manager $x \in X$ to be defined later, $f_{x t}(\cdot)$ is a demand function and $\Theta_{t}$ is the set of parameters and information that is processed to take trading decisions. $\Theta_{t}$ may include the fundamental value $p_{t}^{*}$, lagged price values, various multiples and a series of other data about the state of the economy or the sector in which the firm is operating. In the following discussion we will omit for simplicity $\Theta_{t}$ and consider stylised versions of commonly used strategies based on fundamental analysis, momentum trading that is dependent upon price movements over some prior period and passive index replication whose popularity is due to the preference of the clients for this low-cost investment style. For concreteness, let the set of manager be $X=\left\{F, M_{1}, M_{2}, I\right\}$, whose elements are suggestive of fundamental, momentum (two managers using different look back periods) and index management styles. Making the excess demand proportional to each manager's market share $w_{x t}$ is an effective way to take into account the potential impact on pricing of the demand of the individual managers. While our model has some similarities with Brock and Holmes (1998) and Chiarella et al (2006), where the number (or proportion) of agents of one type affects demand, we use instead the fraction of wealth under management as a natural measure of size. 
The demand of the fundamental manager at time $t$ is given by

$$
f_{F t}\left(p_{t}\right)= \begin{cases}\alpha_{F}\left(\frac{p_{t}^{*}}{p_{t}}-1-\bar{\alpha}\right) & \text { if } \frac{p_{t}^{*}}{p_{t}}-1>\bar{\alpha} \\ 0 & \text { if }\left|\frac{p_{t}^{*}}{p_{t}^{*}}-1\right|<\bar{\alpha} \\ \alpha_{F}\left(\frac{p_{t}^{*}}{p_{t}}-1+\bar{\alpha}\right) & \text { if } \frac{p_{t}^{*}}{p_{t}}-1<-\bar{\alpha}\end{cases}
$$

where $\alpha_{F}$ is a scaling coefficient and $\bar{\alpha}$ defines a no-trading zone when the price $p_{t}$ is too close to the fundamental $p_{t}^{*}$ to allow for profitable trading. Such prudential behaviour of the manager could also be interpreted as a way to incorporate a premium compensating for transaction costs that are not explicitly modelled in this paper. The demand $f_{F t}(\cdot)$ is increasing in the gross return $p_{t}^{*} / p_{t}$ and it is non-negative (non-positive) when $p_{t}^{*} / p_{t}$ is larger (smaller) than 1, capturing the well known intuition that leads to the purchase of undervalued (sale of overvalued) assets.

The demand of the momentum managers is based on a look back period of $h$ weeks. Small values of $h$ are typical of short-term momentum managers, while relatively high values, say $h=26$ or more weeks, are used within longterm trading strategies. We model a simplified version of momentum and assume that the managers buy (sell) stocks only if the realised weekly return over a period of $h$ weeks exceeds (is below) some prespecified rate $^{1} \bar{\alpha}$. Letting $\pi_{t}=\left(\frac{p_{t}}{p_{t-h}}-1\right) / h$ be the weekly return over the past $h$ weeks, the demand function of the momentum managers is

$$
f_{M t}\left(p_{t}\right)= \begin{cases}\alpha_{M} \tanh \left[\beta\left(\pi_{t}-\bar{\alpha}\right)\right] & \text { if } \pi_{t}>\bar{\alpha} \\ 0 & \text { if }\left|\pi_{t}\right|<\bar{\alpha} \\ \alpha_{M} \tanh \left[\beta\left(\pi_{t}+\bar{\alpha}\right)\right] & \text { if } \pi_{t}<-\bar{\alpha}\end{cases}
$$

where $\alpha_{M}$ is a scaling coefficient and $\beta$ measures the speed of reaction to perceived excess growth in the stock returns. We will consider in the following distinct momentum managers, assuming that their strategies differ only in the look-back parameter $h$. The boundedness of the $\tanh (\cdot)$ function ensures that the demand of the momentum managers do not increase without control causing prices to reach extreme levels. This is consistent with evidence that suggests that the signal based on past momentum weakens at its extremities.

The index manager passively replicates the benchmark $p_{t}$. He keeps his stock endowment fixed with no need to alter his portfolio. This is equivalent to saying that his demand function is trivially given by the null function

$$
f_{I t}\left(p_{t}\right) \equiv 0 \text {, for all } t \text {. }
$$

\footnotetext{
${ }^{1}$ To cut down the number of parameters we use the same value $\bar{\alpha}$ that delimits the no-trade zone for the fundamental manager. More nuanced behaviour could easily be implemented with different thresholds for different managers.
} 
If a large amount of wealth is held by the index manager, the available liquidity in the market is seriously reduced with the potential for considerable time to elapse before prices adjust to reflect any new fundamental information that is released to the market.

\subsection{Price dynamics}

We model the evolution of prices as follows. Let $N_{x t}$ and $Q_{x t}$ be the number of stocks held and the cash under management of manager $x \in X$ at (the beginning of) time $t$, when the current price is $p_{t}$. Being $W_{x t}=N_{x t} p_{t}+Q_{x t}$ the wealth managed by $x$, the market shares of the price-taking managers are given by

$$
w_{x t}=\frac{W_{x t}}{\sum_{x \in X} W_{x t}}, x \in X .
$$

These market shares sum to unity and represent the fraction of the total wealth which is controlled by each manager. Excess demands $z_{x t}=$ $w_{x t} f_{x t}\left(p_{t}\right)$ for the risky stock can be computed, aggregated and cleared by the market. The quantities $N_{x, t+1}$ and $Q_{x, t+1}$ are then computed taking into account interest payments, management fees and flows

$$
\begin{aligned}
N_{x, t+1} & =N_{x t}+z_{x t}+\tilde{N}_{x t}, \\
Q_{x, t+1} & =\left(Q_{x t}-z_{x t} p_{t}\right)\left(1+\frac{r_{f}}{13}\right)-\frac{1}{52} F_{x t} \frac{\rho_{x}}{100}+\tilde{Q}_{x t},
\end{aligned}
$$

where $\rho_{x}$ is the management fee rate (in annualised basis points) charged by the given manager on the fee base $F_{x t}=\left(Q_{x t}-z_{x t} p_{t}\right)\left(1+\frac{r_{f}}{13}\right)+\left(N_{x t}+\right.$ $\left.z_{x t}\right) p_{t}$ and $\tilde{N}_{x t}, \tilde{Q}_{x t}$ are additional amount of stock and cash that may result from the periodic decision of some clients to move their holdings ${ }^{2}$. Fees are deducted every week from the cash account of the customer, after interest payments. The amount of the actual imbalance in the aggregate demand

$$
Z_{t}=\sum_{x \in X} w_{x t} f_{x t}\left(p_{t}\right)
$$

is the cause of the change in the price in the next trading session. We assume a very simple price adjusting mechanism loosely inspired by the market maker metaphor (e.g. Day and Huang, 1990).

$$
p_{t+1}=p_{t}\left(1+\mu Z_{t}+\sigma_{\xi} \xi_{t}\right)
$$

where $\mu>0$ is the speed of reaction to the excess demand, $\sigma_{\xi}>0$ and $\xi_{t} \sim N(0,1)$. The impact function (1) updates the price depending on the imbalance in demands by buyers and sellers and the noise term is used to

\footnotetext{
${ }^{2}$ The substantive discussion of the switching by clients is to be found in the following subsection.
} 
incorporate in the price other factors such as exogenous liquidity shocks. More importantly, we allow for the presence of other players in the market and the price is also driven by other agents actively trading in the stock producing "residual" variation described by $\xi_{t}$. Although other price formation mechanisms could be used in place of (1), there are practical and technical advantages in the use of a simple impact function. We model a limited number of managers and representative clients so suggesting that other market mechanisms such as a continuous double auction would have been artificial in such a plain environment. Moreover, it suffices in our setting to model demand alone while demand and limit prices are needed in an order-driven market. Alternatively, prices could be set by equating excess demand to zero, but some difficulties arise due to the existence of multiple clearing prices (due to non linearity of demand). Perhaps more critically, excess demand has discontinuities arising from the dynamic nature of the wealth shares $w_{x t}$ that are possibly changing due to clients switching among managers which is a possibility that will be discussed in the next subsection. An impact function-based price adjustment smooths sudden and unrealistic price movements that occasionally occur by setting excess demand to zero.

The form of (1) allows the price dynamics to be tuned to get some desired properties. For example, suppose that we want the price to revert immediately (i.e., in one trading period) to the fundamental value in a market populated by $100 \%$ fundamentalists and in the absence of noise. This can be obtained easily, setting $\alpha_{F}=\frac{1}{\mu}$ and taking into account that in this setup we have $\sigma_{\xi}=0, w_{F t}=1$ and $w_{x t} \equiv 0$ for all $t, x \neq I$.

\subsection{Customers and switching}

We consider $p$ representative clients that are endowed with some initial wealth that is administered by fund managers of their choice. Clients can use the services of several fund managers at the same time and are characterised by the vector $\tau=\left(\tau_{1}, \ldots, \tau_{p}\right)$ of times (in years) that separate subsequent revisions of their portfolios. Let $N_{i x t}$ and $Q_{i x t}, i=1, \ldots, p$ be the number of stocks and cash managed at time $t$ by manager $x$ on behalf of the $i$-th client so that, for example, the initial wealth of the client $i=1, \ldots, p$ are given by $\sum_{x \in X} N_{i x 0} p_{0}+Q_{i x 0}$.

We assume that clients will revise their allocation among the managers every $52 \tau_{i}$ weeks, switching funds from the worst manager to the most successful one. This performance chasing behaviour of clients mimics a crude learning process in which customers punish the worst results and reward the best ones, leaving unaffected the funds deposited by other, medium ranked, managers. The decisions taken by agents are sharp, in the sense that are based on rank and are not smoothly dependent on some performance measure but, at the same time, they also embed some inertia because middleranking managers (neither the best nor the worst) neither gain nor lose their 
clients.

We assume that switching involves transferring the endowments of stock and cash currently held by one manager to another manager and so involves no transactions in the market. This is akin to common practice as it minimises transfer costs and allows the new manager to revise the portfolio in accordance with their preferences and at a time of their choosing thus avoiding relatively large transactions that could possibly interfere with the price dynamics.

We allow some $\tau_{i}$ to be $\infty$ to mean that the client never revises his initial choice of managers. The behaviour of such a client is then a pure "buy and hold" strategy with respect to their managers in contrast to the switching behaviour of the $i$-th client which is based on the comparison of the performances of the managers undertaken every $52 \tau_{i}$ weeks where the client ranks the managers on the basis of their computed risk-adjusted, after-fee returns relative to the benchmark. He then moves all of his wealth under the management of the worst performing manager to the best performing manager. Notice, that if no wealth is managed by the worst fund, this may result in zero net flow to the best manager, as there is no wealth to move whatsoever. More formally, let $t^{*}=52 k \tau_{i}$ be a revision date ${ }^{3}$ for the agents $i \in S \subseteq\{1, \ldots, p\}$ and denote by $y_{x t}$ the weekly excess return with respect to the benchmark of the fund $x$ at any time $t$ :

$$
y_{x t}=\frac{W_{x t}-D_{x t}}{W_{x, t-1}}-\frac{p_{t}}{p_{t-1}},
$$

where $D_{x t}$ is the net inflow that the fund may have experienced due to switchings at date $t$. Each agent in $S$ computes a performance measure $P_{i x t^{*}}$ for each manager (empirical annualised excess return less standard deviation over a period of $\tau_{i}$ years) as

$P_{i x t^{*}}=52 \operatorname{Avg}\left(\left\{y_{x, t^{*}-52 \tau_{i}-1}, \ldots, y_{x t^{*}}\right\}\right)-\eta \sqrt{52} \operatorname{StDev}\left(\left\{y_{x, t^{*}-52 \tau_{i}-1}, \ldots, y_{x t^{*}}\right\}\right)$,

where $\eta>0$. Based on the previous measure, the client ranks the funds from the best to the worst, denoted by $\bar{x}_{i}$ and $\underline{x}_{i}$, where we omit the reference to $t^{*}$ to simplify notation:

$$
\bar{x}_{i}=\arg \max \left\{P_{i x t^{*}}, x \in X\right\}, \underline{x}_{i}=\arg \min \left\{P_{i x t^{*}}, x \in X\right\} .
$$

The cash and the stock endowment of the switching clients $i \in S$ are then moved from the manager $\underline{x}_{i}$ to $\bar{x}_{i}$. Formally,

$$
\begin{aligned}
& \tilde{Q}_{x t^{*}}=\sum_{i \in S, \bar{x}_{i}=x} Q_{i \underline{x}_{i} t^{*}}-\sum_{i \in S, \underline{x}_{i}=x} Q_{i \underline{x}_{i} t^{*}}, \\
& \tilde{N}_{x t^{*}}=\sum_{i \in S, \bar{x}_{i}=x} N_{i \underline{x}_{i} t^{*}}-\sum_{i \in S, \underline{x}_{i}=x} N_{i \underline{x}_{i} t^{*}} .
\end{aligned}
$$

\footnotetext{
${ }^{3}$ The same $t^{*}$ can be a revision date for more than one agent. If, say, $\tau=(\infty, 1,3,5)$ then $t^{*}=260$ is a revision date for 2 agents $(S=\{2,4\})$ as 260 is divisible by 52 and 260 (1 and 5 years).
} 


\begin{tabular}{r|c|l}
$r_{f}$ & 0.005 & Interest rate (quart.) \\
$r$ & 0.02 & Cost of equity (quart.) \\
$g_{0}$ & 0.01 & Mean growth rate (quart.) \\
$\theta$ & 0.5 & Speed of mean reversion in growth \\
$\sigma$ & 0.01 & Noise in growth \\
$h_{1}, h_{2}$ & 6,26 & Lookback periods of mom. managers \\
$\bar{\alpha}$ & $0.03 / 13$ & No-trade parameter \\
$\alpha_{F}$ & $\frac{1}{\mu}$ & Scaling coefficient of fundamentalist manager \\
$\alpha_{M}$ & 0.025 & Scaling coefficient of momentum managers \\
$\beta$ & 50 & Reaction coefficient of momentum managers \\
$\lambda$ & 0.8 & Payout rate \\
$\mu$ & 1.0 & Speed of reaction of price to excess demand \\
$\sigma_{\xi}$ & 0.02 & Noise in price \\
$\eta$ & 0.5 & Risk adjustment coefficient
\end{tabular}

Table 1: Parameters and brief description (base-case)

If $t$ is not a switching date, then $S=\emptyset$ and, by definition, $\tilde{Q}_{x t}=0=\tilde{N}_{x t}$ for all managers $x \in X$.

\section{Results}

This section presents the results obtained by simulation of the model. All our findings are based on 100 simulations over $T=2500$ weeks, corresponding to roughly 50 years of trading. Unless explicitly noted we consider markets where one fundamental, two momentum and one index managers are available. Hence, $m=4$ and $X=\left\{F, M_{1}, M_{2}, I\right\}$. We assume that there are $p=4$ customers with revision frequencies $\tau=(\infty, 1,3,5)$ years. In general we stipulate a starting situation where each client invests a equal amount with each manger and hence the initial market shares are equal to $25 \%$ for all managers, $w_{x 0}=0.25, \forall x \in X$, and the values of the other parameters are as given in Table 1.

The initial prices $p_{0}=p_{0}^{*}=81.6$ are given in the base-case by the Gordon valuation formula, based on the specified values for the parameters ${ }^{4}$, and we let $N_{i x 0}=4 \cdot 95 w_{x 0}$ and $Q_{i x 0}=4 \cdot 5 w_{x 0} p_{0}$ be the starting stock units and cash amount, so that all funds initially invest $95 \%$ of their wealth in equity.

We start by discussing some possibly unrealistic configurations that are nevertheless very useful in order to see the market dynamics in extreme cases. The next subsection will be devoted to the cases where only fun-

\footnotetext{
${ }^{4}$ To start the simulation, lagged prices for $h=\max \left(h_{1}, h_{2}\right)$ periods are needed by the momentum managers. We set $p_{-j}=\frac{p_{0}}{1+j r_{f} / 13}, j=1, \ldots, h$ so that no initial fake momentum is created.
} 


\begin{tabular}{|c|c|c|c|}
\hline & $\alpha_{M}$ & $\beta$ & Description \\
\hline $\begin{array}{l}\text { Case } 1 \\
\text { Case } 2\end{array}$ & \multicolumn{2}{|c|}{$\begin{array}{l}\text { No switching and no fees } \\
\text { No fees, } \rho=(0,0,0,0)\end{array}$} & Preliminary cases \\
\hline Case 3 & \multirow{2}{*}{\multicolumn{2}{|c|}{$\begin{array}{c}1 \\
0.25\end{array}$}} & Growth process \\
\hline Case 4 & & & \\
\hline Case 5 & & Price dynamics \\
\hline Case 6 & \multicolumn{2}{|l|}{0.5} & \\
\hline Case 7 & \multirow{2}{*}{\multicolumn{2}{|c|}{100}} & Momentum strength \\
\hline Case 8 & & & \\
\hline Case 9 & \multirow{4}{*}{\multicolumn{2}{|c|}{$\begin{array}{c}\text { No switching } \\
70 \% \text { fundam., } w_{F 0}=0.7 \\
w_{M_{1} 0}=w_{M_{2} 0}=w_{I 0}=0.1 \\
\text { Fundam. and index } \\
w_{F 0}=w_{I 0}=0.5 \\
\sigma_{\xi}=0.01\end{array}$}} & Robustness \\
\hline Case 10 & & & \\
\hline Case 11 & & & \\
\hline Case 12 & & & \\
\hline
\end{tabular}

Table 2: Different cases considered

damentalists are present, switching is not allowed and no fees are charged. We then move towards considering a specific set of parameters that we will describe as our "base-case" and which will be shortly discussed in more detail (see Table 1) The time series obtained in the base-case are reasonably realistic, suggesting that the model is capturing many of the actual features of the market. We will then change some key parameter, keeping the others fixed as in the base-case in order to enlighten the features of the model and to provide a robustness analysis of the results. We examine the issues related to the optimal switching frequency (from the point of view of a profit-maximising customer) in Subsection 4.4. The whole design of our simulations is described in Table 2 .

\subsection{Some preliminary cases}

Consider the following extreme situation where the market consists solely of the fundamental manager, $w_{F 0}=1, w_{x 0}=0, \forall x \neq F$, and there is no external noise, that is $\sigma_{\xi}=0$. As noted before, if $\alpha_{F}=1 / \mu$ and $\bar{\alpha}=0$ then the price immediately reacts to the earning announcement and adjusts to the correct fundamental level. In fact, assuming that before the announcement the price and fundamental values are $p$ and $p^{*}$ and that some growth rate $g$ is made public, the new fundamental value (after the announcement) is $(1+g) p^{*}$ and the demand of the unique manager in the market is $f_{F}=$ $\alpha_{F}\left(\frac{(1+g) p^{*}}{p}-1\right)=\frac{1}{\mu}\left(\frac{(1+g) p^{*}}{p}-1\right)$. As there is no other source of demand, this is also the aggregate demand $Z$ and the new price is given by (1) to 
yield

$$
p\left(1+\mu f_{F}\right)=(1+g) p^{*},
$$

proving that the price reverts immediately to the correct new fundamental price. This is as one would expect as we have previously indicated that markets composed of information-based fundamental investors is an important requirement to give rise to efficient pricing within markets. Even when noise is present $\left(\sigma_{\xi} \neq 0\right)$, on average the price is equal to the fundamental value and departures are local and purely driven by idiosyncratic noise.

Consider now a slightly more realistic setting where all four managers commence with an equal share of the market, $w_{x 0}=0.25, \forall x \in X$, but still with no fees charged by managers nor any switching by clients (case 1 in Table 2). The first row of Table 3 shows some statistics relating to the simulations in this case. The volatility of the resulting price is $2.11 \%$ (weekly) and the mispricing, namely the standard deviation of the relative difference of price and fundamental value, is $3.32 \%$. Both the final and the average levels of wealth reported in Table 3 indicate that it is the fundamental manager who gains market share under such a setting. This gain in market share by the fundamental manager is a consequence of him outperforming the other managers. Table 4 reports the excess returns of the managers (left) and of the clients (right), in basis points (bp). In other words, if no fees are charged and clients do not switch between managers, the fundamental manager is able to provide small but persistent superior returns ( $0.5 \mathrm{bp}$ as seen in the left part of the first row of Table 4$)^{5}$.

Allowing now for clients to switch between managers but still in the absence of fees and with equal proportions initially allocated to each of the managers, produces the results of the second row of Tables 3 and 4 (case 2 ). Switching increases the volatility of the price but reduces the level of mispricing, making the market more efficient. This happens because a large fraction of wealth moves from the index to the fundamental manager, as it is evident by reference to the levels of final and average wealth under management as reported in Table 3 . The fractions of wealth managed by the index (fundamental) funds changes on average from $25 \%$ to $6.75 \%$ (25\% to $47.90 \%$ ), respectively, due to the small but sustained superior performance of the fundamental manager. This is confirmed by the performance of managers as reported in Table 4, that shows that the best (worst) manager are likely to be the fundamental (index) manager. The two momentum managers most frequently rank second and third and so neither gain nor lose clients, but when they do rank first or last, the aggregate of their cashflows largely offset each other.

We have so far seen that, when switching is allowed in the absence of fees, the fundamental manager increases his funds under management largely at

\footnotetext{
${ }^{5}$ The reason why the managers underperform the benchmark is that they hold cash in their portfolios whereas the benchmark is entirely composed of one stock.
} 


\begin{tabular}{|c|c|c|c|c|c|c|c|c|c|c|c|}
\hline & \multicolumn{3}{|c|}{ Desc. stats } & \multicolumn{4}{|c|}{$\begin{array}{c}\text { Final wealth } \\
\text { under management }\end{array}$} & \multicolumn{4}{|c|}{$\begin{array}{c}\text { Avg wealth } \\
\text { under management }\end{array}$} \\
\hline & $\begin{array}{c}\text { Price } \\
\text { vol. }\end{array}$ & $\begin{array}{c}\text { Fund. } \\
\text { vol. }\end{array}$ & Mis. & $F$ & $M_{1}$ & $M_{2}$ & $I$ & $F$ & $M_{1}$ & $M_{2}$ & $I$ \\
\hline Case 1 & 2.11 & 0.42 & 3.32 & 25.05 & 24.99 & 24.98 & 24.98 & 25.02 & 24.99 & 24.99 & 24.99 \\
\hline Case 2 & 2.44 & 0.41 & 2.64 & 47.90 & 20.56 & 24.80 & 6.75 & 46.65 & 19.26 & 24.97 & 9.12 \\
\hline Base & 2.07 & 0.41 & 6.04 & 8.19 & 28.04 & 20.56 & 43.22 & 8.40 & 30.73 & 21.57 & 39.30 \\
\hline Case 3 & 2.07 & 0.38 & 5.99 & 8.26 & 27.98 & 20.80 & 42.96 & 8.50 & 29.35 & 21.93 & 40.23 \\
\hline Case 4 & 2.07 & 0.48 & 6.02 & 7.54 & 29.01 & 23.28 & 40.16 & 8.61 & 29.98 & 23.63 & 37.78 \\
\hline Case 5 & 2.06 & 0.41 & 7.47 & 9.31 & 26.56 & 19.82 & 44.30 & 9.13 & 28.66 & 22.02 & 40.18 \\
\hline Case 6 & 2.11 & 0.42 & 4.02 & 7.14 & 26.48 & 22.14 & 44.24 & 7.88 & 28.96 & 22.62 & 40.54 \\
\hline Case 7 & 2.33 & 0.41 & 11.21 & 10.34 & 22.98 & 18.07 & 48.61 & 9.82 & 27.67 & 21.69 & 40.83 \\
\hline Case 8 & 2.13 & 0.41 & 8.00 & 7.71 & 27.63 & 22.64 & 42.02 & 8.84 & 28.84 & 23.51 & 38.81 \\
\hline Case 9 & 2.16 & 0.41 & 2.88 & 23.48 & 24.96 & 24.96 & 26.60 & 24.12 & 24.98 & 24.98 & 25.91 \\
\hline Case 10 & 2.15 & 0.41 & 3.17 & 18.18 & 10.24 & 8.89 & 62.69 & 20.54 & 11.34 & 9.60 & 58.52 \\
\hline Case 11 & 2.08 & 0.41 & 4.08 & 13.83 & - & - & 86.17 & 16.49 & - & - & 83.51 \\
\hline Case 12 & 1.03 & 0.41 & 2.84 & 7.42 & 23.48 & 20.98 & 48.12 & 8.12 & 26.12 & 23.59 & 42.17 \\
\hline
\end{tabular}

Table 3: Descriptive statistics and flows (averaged across 100 simulations of 5000 weeks). The first three columns show the percentage standard deviation of price, growth rate and the relative mispricing (standard deviation of $\left.\frac{p_{t}-p^{*}}{p^{*}}\right)$. The columns 4-7 (8-11) report the final (time-averaged) wealth for each manager.

the expense of the index manager. At the same time, switching on the part of customers is beneficial to the efficiency of the market, as it is moving more funds to the unique trader that correctly impounds fundamental information into prices. However, the price produced in all of the previously discussed environments is not realistic as the returns are strongly negatively correlated $^{6}$. This is almost trivial given that most of the trading is undertaken by the fundamental manager and the price quickly reverts to the fair valuation as soon as it departs from it for some reasons. Moreover, the assumption of no fees is clearly at odds with reality and in the following section we examine a much more realistic case where clients switch among managers (chasing after-fees performance).

\subsection{The base-case}

In this subsection we introduce a set of reasonable fee levels for each manager that reflect both the costs and the risks associated with realizing their par-

\footnotetext{
${ }^{6}$ Cont (2001) and Pagan (1996) are good surveys of the common properties of financial time series (also known as stylized facts).
} 


\begin{tabular}{c|cccc|cccc} 
& \multicolumn{4}{|c|}{ Performance of } & \multicolumn{4}{c}{ Performance of } \\
& \multicolumn{4}{|c}{ managers (bp) } & \multicolumn{4}{c}{ customers (bp) } \\
\hline & $F$ & $M_{1}$ & $M_{2}$ & $I$ & $\tau=\infty$ & $\tau=1$ & $\tau=3$ & $\tau=5$ \\
Case 1 & -6.12 & -6.61 & -6.65 & -6.68 & -6.48 & -6.48 & -6.48 & -6.48 \\
Case 2 & -6.28 & -6.48 & -6.48 & -6.58 & -6.35 & -6.28 & -6.32 & -6.33 \\
Base & -36.24 & -26.79 & -26.39 & -11.86 & -25.99 & -22.73 & -20.21 & -20.22 \\
Case 3 & -34.21 & -25.88 & -25.59 & -11.66 & -25.15 & -21.96 & -19.41 & -19.60 \\
Case 4 & -36.87 & -26.68 & -26.53 & -11.63 & -25.91 & -22.82 & -20.51 & -20.17 \\
Case 5 & -34.85 & -26.34 & -26.16 & -11.44 & -25.68 & -22.59 & -19.91 & -19.77 \\
Case 6 & -35.33 & -26.07 & -25.74 & -11.96 & -25.29 & -21.68 & -19.41 & -19.71 \\
Case 7 & -33.76 & -26.68 & -26.60 & -10.71 & -25.76 & -22.41 & -20.13 & -20.21 \\
Case 8 & -34.20 & -26.07 & -25.94 & -11.45 & -25.33 & -22.49 & -19.93 & -19.75 \\
Case 9 & -38.84 & -26.10 & -26.14 & -12.91 & -25.95 & -25.95 & -25.95 & -25.95 \\
Case 10 & -37.13 & -26.23 & -26.14 & -11.56 & -33.49 & -17.10 & -16.04 & -16.69 \\
Case 11 & -35.77 & - & - & -11.90 & -24.98 & -15.39 & -13.46 & -13.71 \\
Case 12 & -37.09 & -26.10 & -25.95 & -11.80 & -25.67 & -20.85 & -19.56 & -19.78
\end{tabular}

Table 4: Performance of managers (left) and customers (right). In detail, the annualized excess return with respect to benchmark $p_{t}$ is shown. $\mathrm{Al}$ figures are expressed in basis points (bp).

ticular strategy: the fee structure that we implement is $\rho=(50,30,30,10)$ bp. This then becomes our base-case and we examine the impact of these fees on the volatility of the price, mispricing, flows among the managers and performances of funds and customers. Table 1 contains the values of the parameters of this base-case.

The plot of the actual (benchmark) price $p_{t}$ and the fundamental price (in red) in Figure 1 clearly establishes the existence of a strong relationship between the two sets of prices but it also highlights there are persistent and sizeable deviations between the two. The quarterly growth rate in earnings over time as depicted in the left lower panel of Figure 1 highlights the the mean-reverting nature of the earning process around the quarterly long term mean $g_{0}=1 \%$ (in red) which give rise to excursions that are "misinterpreted" by momentum traders and fuel sustained trading. Observe that the earnings growth rate is constant between two announcement dates and that there are episodes of prolonged negative outcomes that cause a reduction in the fundamental price. Despite the correlation in the earnings growth rates, that is driving the price, and the presence of fundamental and momentum managers that should induce negative and positive correlation, respectively, the returns of the benchmark are uncorrelated as shown in Figure 1 on the right $^{7}$. The extreme weakness of the linear structure makes the price virtu-

\footnotetext{
${ }^{7} \mathrm{~A}$ Box-Ljung test with 10, 20, 30 lags cannot reject at the $1 \%$ confidence level the
} 

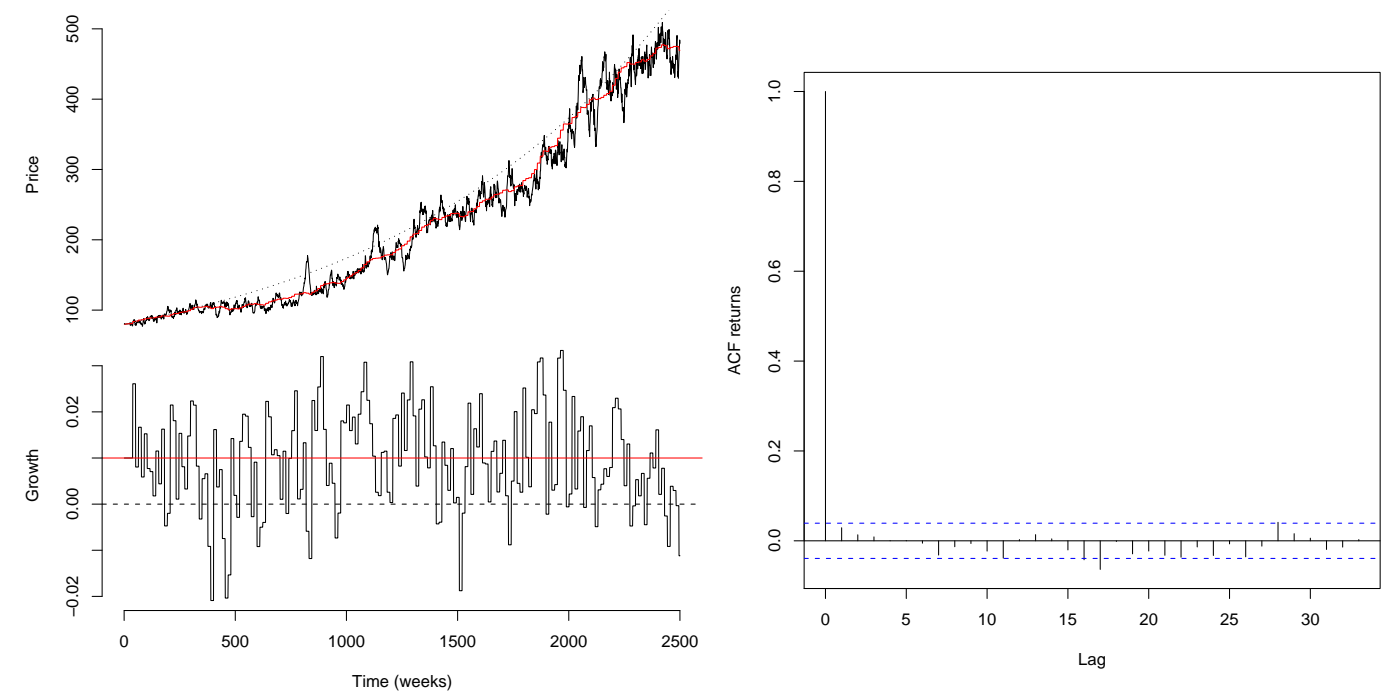

Figure 1: Benchmark (black) and fundamental price (red), left upper panel. Growth rate in black, left lower panel. The level of $g_{0}=0.01$ is depicted as a red horizontal line. The right graph shows the autocorrelation function of the benchmark returns.

ally unpredictable using linear models based on past observations and this is a robust feature of all the simulations in this parameters' configuration ${ }^{8}$.

The mispricing of $6.04 \%$ for this base case, as seen in Table 3, is much larger than that reported for the two cases discussed in the previous subsection where there were no management fees charged. Hence, the introduction of the fees appears to be responsible for a decrease in the efficiency of the market. The density of the mispricing shown in Figure 2 is not symmetric around zero with there being more instances where the actual price is below the fundamental value. This is to be expected as, on average, earning announcements increase the fundamental value and the price is left behind, taking some time to recover. On the other hand, the same effect is ultimately responsible for the fat right tail. Normally, the fundamental manager is accountable for the initial increase of the price after a positive earning rate is made public and the subsequent movement in the actual price over time towards the fundamental price. This trend in price triggers the entry of the momentum managers who subsequently push the actual price well beyond the fundamental price.

The right exhibit of Figure 2 documents the autocorrelation of the mis-

null hypothesis of linear independence of the price, producing $p$-values of $0.709,0.063$ and 0.019 .

${ }^{8}$ The following subsection will examine situations where some linear predictability can unavoidably be detected due to the large weight of the fundamental manager or due to the massive activity of the momentum managers. 

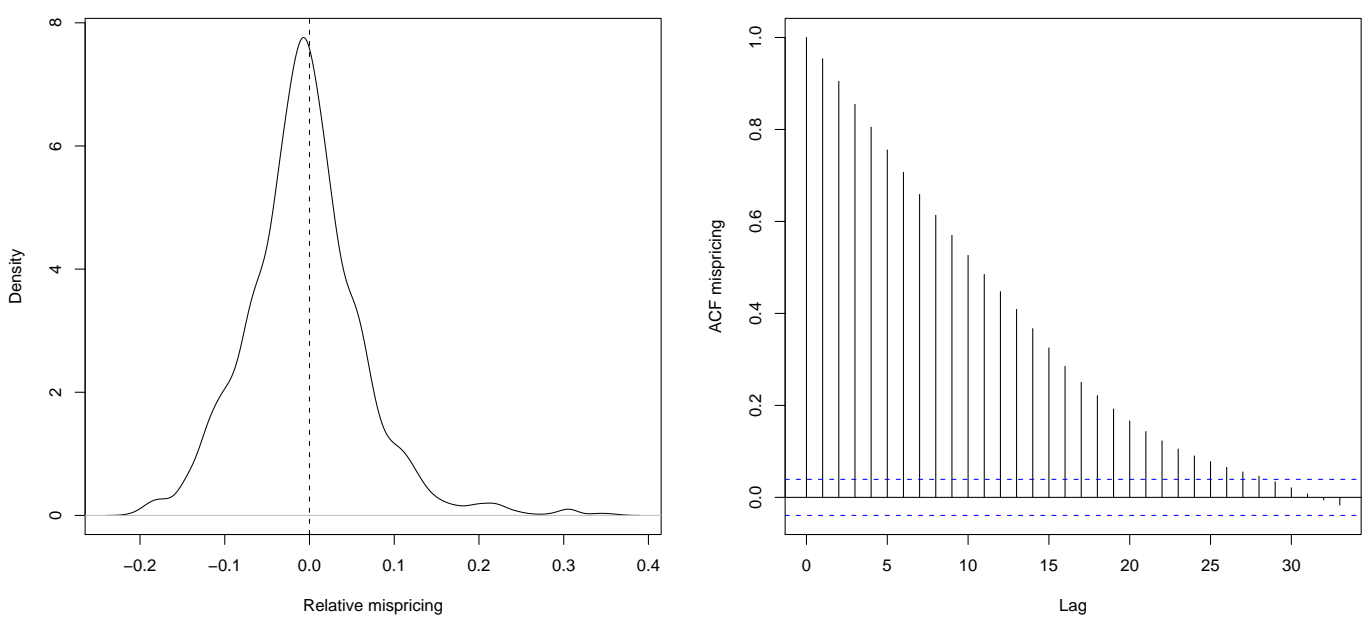

Figure 2: Density of the mispricing. The mode of the distribution is negative and there are examples of "bubbles" where the price exceeds the fundamental value by more than $30 \%$.

pricing, establishing that a large deviation between the actual price and the the fundamental price at time $t$ is likely to persist over an extended time period. This reflects that only a minority of the demand is coming from the fundamental manager with the possibility that some of the other managers are taking an opposing stance.

A representation of the flow dynamics is depicted in Figure 3 with the index manager (in blue) initially attracting funds from the fundamental manager as the jumps in his wealth under management clearly show. In this instance, the index fund loses a portion of his wealth between weeks 1000-1500, when the long-term momentum manager (in green) outperforms the short-term fund (in red, initially covered by the green line). At the end of this simulation the managers $\left(\mathrm{F}, \mathrm{M}_{1}, \mathrm{M}_{2}, \mathrm{I}\right)$ retain $5.8 \%, 12.3 \%, 30.8 \%$ and $51.1 \%$ of the wealth, respectively.

The middle (right-hand) portion on the right of Table 3 reports the final (average) proportion of the total wealth under management by each of the four managers, averaged over 100 simulations per case. The base-case row shows that the index fund is on average managing $39.30 \%$ of the total wealth, to be contrasted with the initial proportion of $25 \%$ (constant for all funds). Due to our switching mechanism, the index manager who frequently ranks first wins funds off the fundamental manager who often is the worst performer as revision dates. With some exceptions demonstrated by weeks 1352 and 1404 in Figure 3, when the short-term manager looses funds to the advantage of the fundamental and index ones, the two momentum funds 


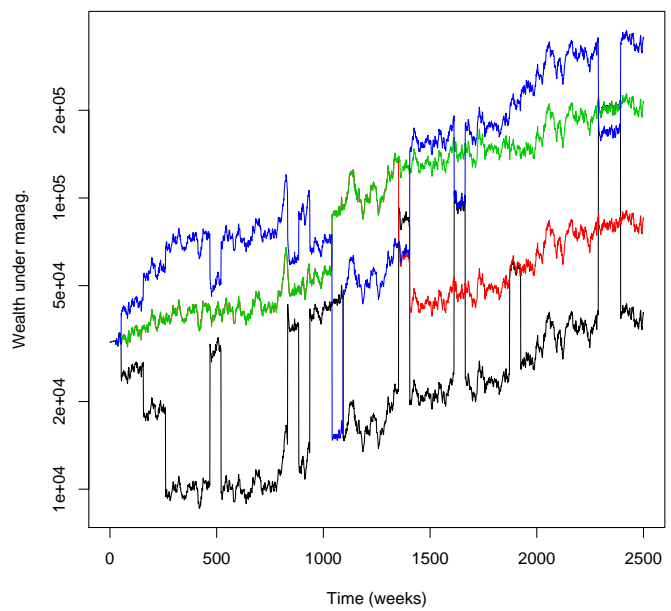

Figure 3: Wealth under management for the different funds. The wealth of the fundamental, short/long-term momentum and index managers are shown in black, red, green and blue. Notice the log scale on the $y$-axis.

most commonly rank second or third and thus avoid in- and out-flows.

The base-case row of Table 4 reports on the left (right) the after-fees annualised excess returns (in basis points) of the managers (clients). The fundamental manager is losing -36.24 bp per year relative to the benchmark and it is clearly outperformed by the index manager and both momentum managers. Given that the volatilities of the excess returns are approximately the same for all funds, such low performance explains the flow to the index manager.

The conclusion that the fundamental managers is the worst of the managers needs to be qualified after taking into account the fees levied. Losing $36.24 \mathrm{bp}$ per year after $50 \mathrm{bp}$ of fees actually (albeit crudely) means that the manager is able to generate a positive excess return of $13.76 \mathrm{bp}$ before-fees under the base-case. For comparison the excess return before-fees of the other managers are $3.21,3.61$ and $-1.86 \mathrm{bp}$. The momentum managers can generate a limited excess profit, exploiting the pseudo-cycles generated by the earning announcement process and their own herding. Not surprisingly, the index manager is unable, by definition, to reap gains. The flows away from the fundamental manager are not due to his lack of skills but rather to the simple fact that he is deserted by his performance-chasing clients as a consequence of his outperformance being insufficient to cover the costs associated with implementing a fundamental strategy.

The negative after-fees performances of the fundamental manager will be further discussed in the final section. In the next sub-section we perform 
an extensive robustness analysis of our results by way of varying the values of several parameters.

\subsection{Robustness analysis}

We explore in this subsection the sensitivity of our results to variations in the base-case parameters. Simulations are undertaken to determine whether, our findings are affected by i) changes in the process for generating earnings; ii) variation in the speed of price adjustment; iii) changes in the aggressiveness of trading by momentum managers and iv) modifications of several other parameters.

Cases 3 and 4 change the mean-reversion coefficients of the growth process for earnings. When $\theta=1$ earnings are uncorrelated while if $\theta=0.25$, the correlation in the announcements increases relative to the base-case. In both cases, negligible changes are found in volatility, mispricing, flows and performance, showing that finer details in the earnings' generation process are unlikely to be relevant.

Changing the speed of adjustment $\mu$ of the price relative to demand imbalances can have important consequences for the results. In case 5 we increase $\mu$ by 0.5 while we decrease it by the same amount in Case 6 . As expected, more reactive prices movements inflate the mispricing to almost $7.5 \%$ (case 5 ), while smoother adjustments $(\mu=0.5$, case 6$)$ reduce it to $4 \%$. The previously shown patterns in flows and performance are, however, rather stable: we still see a definite movement away from the fundamental towards the index manager. Overall, there is little doubt that the basic findings holds over a fairly wide range of values for $\mu$.

Cases 7 and 8 explore some of the parameters of the demand function of the momentum managers. In both cases, the impact of momentum-driven demand is increased if compared to the base-case. The demand of the momentum managers is proportional to $\alpha_{M}$. In a related (but subtly different) way, increasing $\beta$ raises the sensitivity to the momentum that is needed in order to buy/sell a given quantity of the asset. Unsurprisingly, inflating the demand of the momentum investors generated by any given signal has some disruptive effects, as the volatility and, in particular, the level of mispricing increases. Larger deviations from the fundamental price are observed and the time series exhibit wide swings and some pseudo-cyclic behaviour. Observe that this increased aggressiveness of the momentum investors produces mild, but statistically significant, positive serial correlation in the returns. As far as the flows are concerned, the increased activity of the momentum managers does not always equate with an increase in their wealth under management, that is indeed reduced in case 7 and remains approximately the same for the aggregate of two momentum funds in case 8, even though there is a slight improvement in their performance. The reason that the improved performance does not translate into more funds under manage- 
ment is due to an increase in the volatility of the returns of the momentum managers that impacts on their risk-adjusted performance.

The final cases, from 9 to 12, are testing the model under several other variations of the base-case parameters. For instance, the inability to switch in Case 9 results in a reduction in client returns by about 5 bp per year relative to the base case. Interestingly, in a market where fees are charged, the absence of switching would result in the level of mispricing being halved relative to the base case but we do not believe that clients behaviour is driven by the efficiency of markets but rather by the possibility of realising individual gains.

In case 10 , the fundamental manager has initially a very large fraction of the funds under management, $70 \%$, while the other managers equally share the remaining $30 \%$. Not surprisingly, the market prices become more efficient with the greater influence of the fundamental manager but again we see the large transfer of funds under management from the fundamental manager to the index manager. This finding is confirmed under case 11 where only the fundamental and the index manager are available to clients, i.e. $X=\{F, I\}$.

Finally, case 12 shows that our findings are robust to a change of the size $\sigma_{\xi}$ of the exogenous noise that contributes to the price adjustment.

\subsection{The role of switching}

It is of great interest to examine the importance of switching for profitchasing clients. An examination of the right section Table 4 shows that noswitching $(\tau=\infty)$ is an inferior strategy relative to the switching strategy of the other three clients. Reviewing their managers every $\tau=3$ or $\tau=5$ years produces very similar performances that are preferable to switching every year (column $\tau=1$ ), with small additional returns of 1 to $2.5 \mathrm{bp}$ in most cases.

A low frequency revision and switching strategy provides gains ranging from about $6 \mathrm{bp}$ in the base-case to almost $20 \mathrm{bp}$ per year in case 10, if compared to the buy-and-hold strategy of $\tau=\infty$ (i.e. Case 9). In other words, there is evidence that evaluating managers periodically every 3 or 5 years and switching accordingly yields statistically greater returns with respect to the no-switching option. The economic significance of this result is, however, less evident. Even in our setting, where we compare managers that use different investment styles but keep an average identical exposure to equity ( $95 \%$ of the wealth) so that large differences in returns are unlikely, a few basis points may not be enough to justify portfolio reallocation. Some back-of-the-envelope computations, for example, show that revising every 5 years is on average producing $5 \cdot 5.8=29$ bp of cumulated excess gains in the base-case. Small switching costs, even of psychological or cognitive type, would totally wipe out the gains arising from reallocation on the part 
of the customer that may just be satisfied with a constant mix.

\section{Conclusions}

One characteristic of modern equity markets is that they are populated by managers pursuing a range of investment styles. Even more importantly, many of these styles utilise little or none of the available information and so bring into question the extent to which information will be quickly impounded into prices. Indeed, available evidence suggests that many of these styles, but particularly momentum investing, are disruptive to the pricing within these markets. One question that this raises is the longevity of this situation with the possibility that a learning process that operates in these markets will result in the demise of the offending managers and so result in a return to efficient markets dominated by information-based investors.

In this paper we investigate a market composed of fundamental, momentum and index managers who manage funds on behalf of several clients. Learning in our model comes by way of the clients who in the pursuit of better investment returns periodically switch their funds from the worstperforming manager to the best-performing manager. Another important aspect of our model is the fact that managers charge for their services to not only recover their costs but also to generate a fair level of profit. Our simulations show that in such an environment, switching actually contributes to the mispricing as funds actually flow from the stabilising fundamental manager to the index manager as a result of their inferior after-fee performance attributable to their higher cost structure. In other words a combination of costly active management with performance-chasing clients leads to sustainable and extended mispricing within markets. Further, we confirm that these findings are not simply a consequence of the parameterisation of our base case and are likely to be representative of today's equity markets that feature managers pursuing a diverse range of investment styles, who charge for their services and who manage on behalf of clients whose main concern is to maximise the after-fees returns on their investments.

Other findings that can be drawn from our simulations include confirmation that it is the momentum managers that are the main destabilising force within markets, that index funds might be the most cost-effective means for managing funds but that their presence does contribute to inefficiencies in the pricing within markets, and that switching based on past performance might appear to offer an opportunity to enhance investment returns but any improvement is likely to be largely wiped out by switching costs. 


\section{References}

Arthur, W.B. (1995). Complexity in economic and financial markets. Complexity, 1, 20-25.

Beltratti, A. and Margarita, S. (1992). Evolution of trading strategies among heterogeneous artificial economic agents, in Meyer, J.A., Roitblat, H.L., and Wilson, S.W., eds. From animals to Animats 2. M.I.T. Press. Cambridge, MA.

Berk, J.B. and Green, R.C. (2004). Mutual fund flows and performance in rational markets. Journal of Political Economy, 112. 6. 1269-1295.

Bird, R., He, X, Thosar, S. and Woolley, P. (2005). The Case for market Efficiency: Investment Style and Market Pricing. Journal of Asset Management, 5. 365-388.

Black, F. (1986). Noise. Journal of Finance, 41. 529-543.

Brock, W.A., and Hommes, C.H. (1997). A rational route to randomness. Econometrica, 65. 1059-1095.

Brock, W.A., and Hommes, C.H. (1998). Heterogeneous beliefs and routes to chaos in a simple asset pricing model. Journal of Economic Dynamics and Control, 22. 1235-1274.

Brock, W.A., and LeBaron, B. (1996). A structural model for stock return volatility and trading volume. Review of Economics and Statistics, 78. 94110 .

Bu, Q. and Lacey. N. (2008). Do mutual funds exhibit a smart money effect? Quarterly Journal of Finance and Accounting, 47. 5368.

Chiarella, C., He, X., Hommes, C. (2006). A dynamic analysis of moving average rules. Journal of Economic Dynamics and Control, 30. 9-10. 17291753.

Cont, R. (2001). Empirical properties of asset returns: stylized facts and statistical issues. Quantitative Finance, 1. 223-236.

Day, R.H. and Huang, W. (1990). Bulls, bears and market sheep. Journal of Economic Behavior and Organization, 14. 299-329.

Fama, E.F. (1970). Efficient capital markets: A review of theory and empirical work. Journal of Finance, 25. 383-417.

Farmer, J.D. and Joshi, S. (2002). The price dynamics of common trading strategies. Journal of Economic Behavior and Organization, 49. 149-171.

Figlewski, S. (1978). Market "efficiency" in a market with heterogeneous information. Journal of Political Economy, 86. 4. 581-597.

Grossman, S.J. (1976). On the efficiency of competitive stock markets where traders have different information. Journal of Finance, 31. 573-585.

Grossman, S.J. (1977). The existence of future markets, noisy rational expectations and informational externalities. Review of Economic Studies, 44. 3. 431-449.

Grossman, S.J. and Stiglitz, J.E. (1980). On the impossibility of informationally efficient markets. American Economic Review, 70. 393-408. 
Gruber, M.J. (1996). Another puzzle: The growth in actively managed mutual funds. Journal of Finance, 51. 3. 783-810.

$\mathrm{He}, \mathrm{X}$. and Li, Y. (2008). Heterogeneity, profitability and autocorrelations. Quantitative Finance, 8. 1. 59-79.

Hommes, C.H. (2001). Financial markets as nonlinear adaptive evolutionary systems. Quantitative Finance, 1, 149-167.

Hommes, C.H. (2006). Heterogeneous agent models in economics and finance. In Judd, K.L. and Tesfatsion, L. eds, Handbook of Computational Economics, vol. 2, chap. 23.

Hong, H. and Stein, J.C. (1999). A unified theory of underreaction, momentum trading and overreaction in asset markets. Journal of Finance, 54. 2143-2184.

Iori, G. (2002). A microsimulation of traders' activity in the stock market: the role of heterogeneity, agents' interactions and trade frictions. Journal of Economic Behavior and Organization, 49. 269-285.

Lettau, M. (1997). Explaining the facts with adaptive agents: The case of mutual fund flows. Journal of Economic Dynamics and Control, 21. 11171148.

Lux, T. (1995). Herd behaviour, bubbles and crashes. The Economic Journal, 105. 881-896.

Lux, T. (1998). The socio-economic dynamics of speculative markets: interacting agents, chaos, and the fat tails of return distribution. Journal of Economic Behavior and Organization, 33. 143-165.

Lux, T. and Marchesi, M. (1999). Scaling and criticality in a stochastic multi-agent model of a financial market. Nature, 397. 498-500.

Lux, T. and Marchesi, M. (2000). Volatility clustering in financial markets: a micro-simulation of interacting agents. International Journal of Theoretical and Applied Finance, 3. 675-702.

Pagan, A. (1996). The econometrics of financial markets. Journal of Empirical Finance, 3. 15-102.

Sapp, T,. and Tiwarim A. (2004) Does Stock Return Momentum Explain the "Smart Money" Effect? Journal of Finance, 59, 26052622.

Sargent, T.J. (1993). Bounded rationality in macroeconomics. Clarendon Press. Oxford.

Schumpeter, J. (1934). The theory of economic development. An inquiry into profits, capital, credit, interest, and the business cycle. Harvard University Press. Cambridge. Seventh printing, 1961.

Sirri, E.R. and Tufano, P. (1998). Costly search and mutual fund flows. Journal of Finance, 53, 1589-1622.

Soffer, L. and Walther, B. (1999). Returns momentum, returns reversals and earnings surprises University of Illinois at Chicago. Technical report.

Zheng, L. (1999) Is Money Smart? A Study of Mutual Fund Investors' Fund Selection Ability. Journal of Finance, 54, 901-904 